\title{
An Observation of Racial and Gender Disparities in Congestive Heart Failure Admissions Using the National Inpatient Sample
}

\author{
Varun Tandon ${ }^{1}$, Bryan Stringer ${ }^{2}$, Chad Conner ${ }^{2}$, Andre Gabriel ${ }^{3}$, Byomesh Tripathi ${ }^{1}$, Kathir
} Balakumaran $^{4}$, Kai Chen ${ }^{5}$

1. Cardiology, University of Arizona College of Medicine, Phoenix, USA 2. Internal Medicine, University of Connecticut Health, Farmington, USA 3. Cardiology, West Virginia University, Morgantown, USA 4. Cardiology, University Hospitals, Cleveland, USA 5. Cardiology, University of Connecticut Health, Farmington, USA

Corresponding author: Bryan Stringer, bstringer@uchc.edu

\section{Abstract \\ Background}

Congestive heart failure (CHF) is a frequent cause of inpatient admissions in the United States. The purpose of this study was to analyze the racial and gender disparities that occur in CHF admissions and determine the impact of these disparities on medical expenditure.

\section{Methods}

We analyzed the National Inpatient Sample (NIS) database from 2009 to 2014 for patients with a primary discharge diagnosis of CHF, and further stratified the cohort on the basis of race and sex. Multivariate analysis was performed to identify the association between CHF and total charges along with other variables such as mortality, length of stay (LOS), and number of procedures.

\section{Results}

There were a total of 5,491,050 admissions with a primary diagnosis of CHF from 977,850 in 2009 to 901,425 in 2014. Females accounted for $49.7 \%$. Total charges for CHF admission were highest in Asians at an average cost of $\$ 59,668$. African Americans had the lowest mortality rate at $1.75 \%$, however, they also had an average age of admission of 63.47 years, compared to Caucasian at $76.76(\mathrm{p}<0.05)$. Total charges for males were $\$ 42,920$ and $\$ 36,744$ for females ( $<<0.05$ ). Males also had more procedures at 1.16 vs 0.98 for females ( $p$ $<0.05)$. Elixhauser mortality score was higher in males than females at 5.95 vs $5.42(\mathrm{p}<0.05)$.

\section{Conclusion}

Healthcare disparities exist in CHF admissions in both contexts of race and gender. Further studies are required to pinpoint the source of these differences not only to address mortality but also expenditure costs.

Review began 09/12/2020 Review ended 10/08/2020 Published 10/12/2020

๑) Copyright 2020

Tandon et al. This is an open access article distributed under the terms of the Creative Commons Attribution License CC-BY 4.0., which permits unrestricted use, distribution, and reproduction in any medium, provided the original author and source are credited.
Categories: Cardiology

Keywords: cardiology, congestive heart failure, healthcare disparities

\section{Introduction}

Heart failure is a leading cause of hospitalizations and readmissions in the United States [1,2]. According to the Centers for Disease Control and Prevention (CDC), there were over 2 million hospitalizations for congestive heart failure (CHF) in 2016 with an estimated cost of 32.7 billion dollars [3]. This represents a significant contribution to healthcare expenditure in the United States that exceeds 3.5 trillion dollars according to the Center for Medicare and Medicaid Services (CMS) [4]. The prevalence of CHF is expected to continue to increase by $46 \%$ from 2012 to 2030 [5]. This increasing prevalence of heart failure will only add to the burden of an already expensive US healthcare system. Research has been done to investigate factors that contribute to excess cost with increased emphasis on factors such as healthcare disparities.

Healthcare disparities are defined as differences in the quality of health care that are not due to accessrelated factors or clinical needs, preferences, and appropriateness of interventions according to the institute of health [6]. Previous research has shown that many healthcare disparities are associated with excess cost in racial minorities, which include African American, Asian American, Pacific Islander, Native American, and Hispanic. The total estimated cost of these disparities is over 1 trillion dollars [7]. This represents a significant contribution to the overall cost of healthcare in the United States and indicates an area that can be improved significantly.

The reasons for healthcare disparities are complex. It involves patient, provider, and system-specific factors 
[8]. Patient-specific factors include their genetics in addition to their behaviors. For example, African American and Hispanic populations have higher rates of diabetes mellitus and hypertension, impacting their incidence of $\mathrm{CHF}$, in addition to co-morbidities that impact health outcomes [9]. Provider-specific factors include unintentional biases and varying degrees of sensitivity to patient-specific cultural backgrounds. One reason for this could be explained by their own cultural background [10]. System factors include access to healthcare, insurance coverage, and infrastructure limitations [8]. Some of these factors have been addressed including an increased number of Americans with health insurance under the Affordable Healthcare Act legislation [11]. Given that healthcare disparities have contributed vastly to the cost of the healthcare system, further research needs to be done to better understand these factors and the impact they have on individual patients and the overall cost of healthcare in the United States.

Our study aimed to identify differences in inpatient mortality, total charges, and other variables among those admitted for CHF exacerbation. The rationale behind the focus on heart failure is mainly due to its high prevalence as well as the CMS focus on reducing 30-day readmission rates. We hope to highlight the financial impact of racial and sex disparities in healthcare to inspire further research and interventions to close this gap in the future.

\section{Materials And Methods \\ Data source}

Data was queried via the National Inpatient Sample (NIS) developed in part by the Healthcare Cost and Utilization Project (HCUP). The NIS database is one of the largest publicly available all-payer databases in the United States. The dataset per year represents approximately 35 million hospital admissions nationally.

\section{Study population}

A retrospective observational analysis was done by means of the NIS database from the year 2009 to 2014 . Clinical Classification Software (CCS) code 108 was used to identify a primary diagnosis code representing CHF for the hospitalization. This code includes both populations of systolic and diastolic heart failure in order to study any patient with an active heart failure admission. Patients with CCS codes of 108 as a nonprimary category code were excluded as such to remove the possibility of a non-active issue during hospitalization.

\section{Variables}

Patients diagnosed with active CHF as the principal diagnosis during hospitalization were then stratified by their race and sex. Within each race and sex, we identified the incidence, in-hospital mortality, and age. Total hospital charges, total number of procedures during hospitalization (NPR), and length of stay (LOS) were also analyzed. We additionally identified the income quartile based on the patient's residential zipcode. Income by quartile is a scale where a score of 1 represents income from 0 -25th percentile, 2 equals 26 th to 50 th percentiles, 3 equals 51 st to 75 th and 4 equals 76 th to 100 th percentiles. Furthermore, insurance types were analyzed in each race. In-hospital mortality scores were based on the Elixhauser Comorbidity Index, which is a dichotomous method of categorizing comorbidities of patients based on the International Classification of Disease (ICD) codes. Comorbidities were established using the Elixhauser determined comorbidities.

\section{Statistical analysis}

Statistical analyses were performed using SAS ${ }^{\circledR}$ software, version 9.4 (SAS Institute, Cary, North Carolina). Weights provided by HCUP were applied to generate national estimates. Categorical variables were analyzed using Chi-square (X2) analysis and continuous variables were tested using analysis of variance (ANOVA). For further delineation of analysis, multivariate regression was also used to determine inter-racial discrepancies and disparities. The level of statistical significance $(\alpha)$ was chosen as $5 \%$.

\section{Results}

In this retrospective study of data, 5,491,050 patients were identified from the NIS database between 2009 and 2014 who were admitted with CHF as the primary diagnosis code. Over the course of the study, there was a slight overall decrease in CHF admissions per year from 977,850 in 2009 to 901,425 in 2014 (Figure 1). Overall, women comprised $49.7 \%$ of CHF admissions between 2009 and 2014 . Caucasians constituted a majority of CHF admissions at $68.4 \%$. This was followed by African Americans at $19.2 \%$, Hispanics at $7.6 \%$, Asians at $1.8 \%$, and Native Americans at $0.6 \%$. The average age of patients with CHF admissions was relatively stable over time: in 2009 the mean age was 72.93 years vs 72.16 years in 2014 , with women being older than men across all races (Figure 2). Furthermore, the average mortality rate for CHF admissions amongst all races was $3.09 \%$. The average LOS did not change significantly (5.23 days in 2009 vs 5.24 days in 2014). Nonetheless, the average total cost charged was noted to increase over time: from $\$ 35,572$ in 2009 to $\$ 44,316$ in 2014 . 


\section{Cureus}

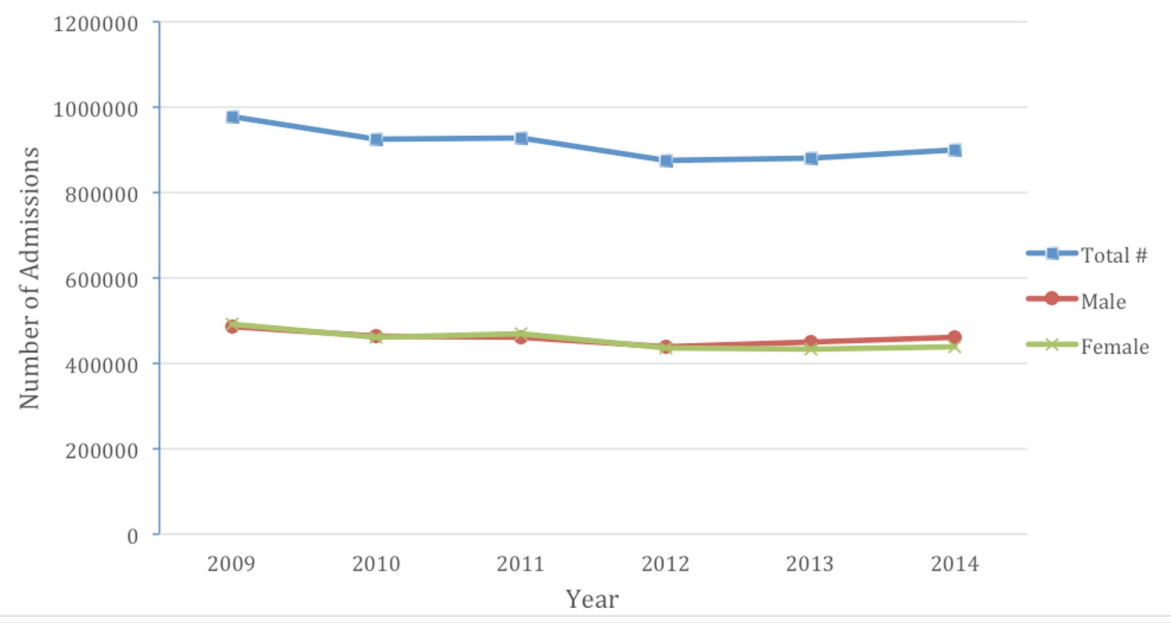

FIGURE 1: Total number of congestive heart failure (CHF) admissions by year

A decrease in overall CHF admissions was noted from 2009 to 2014. This same decrease was also noted between genders with males have more admissions for CHF in 2014 than females.

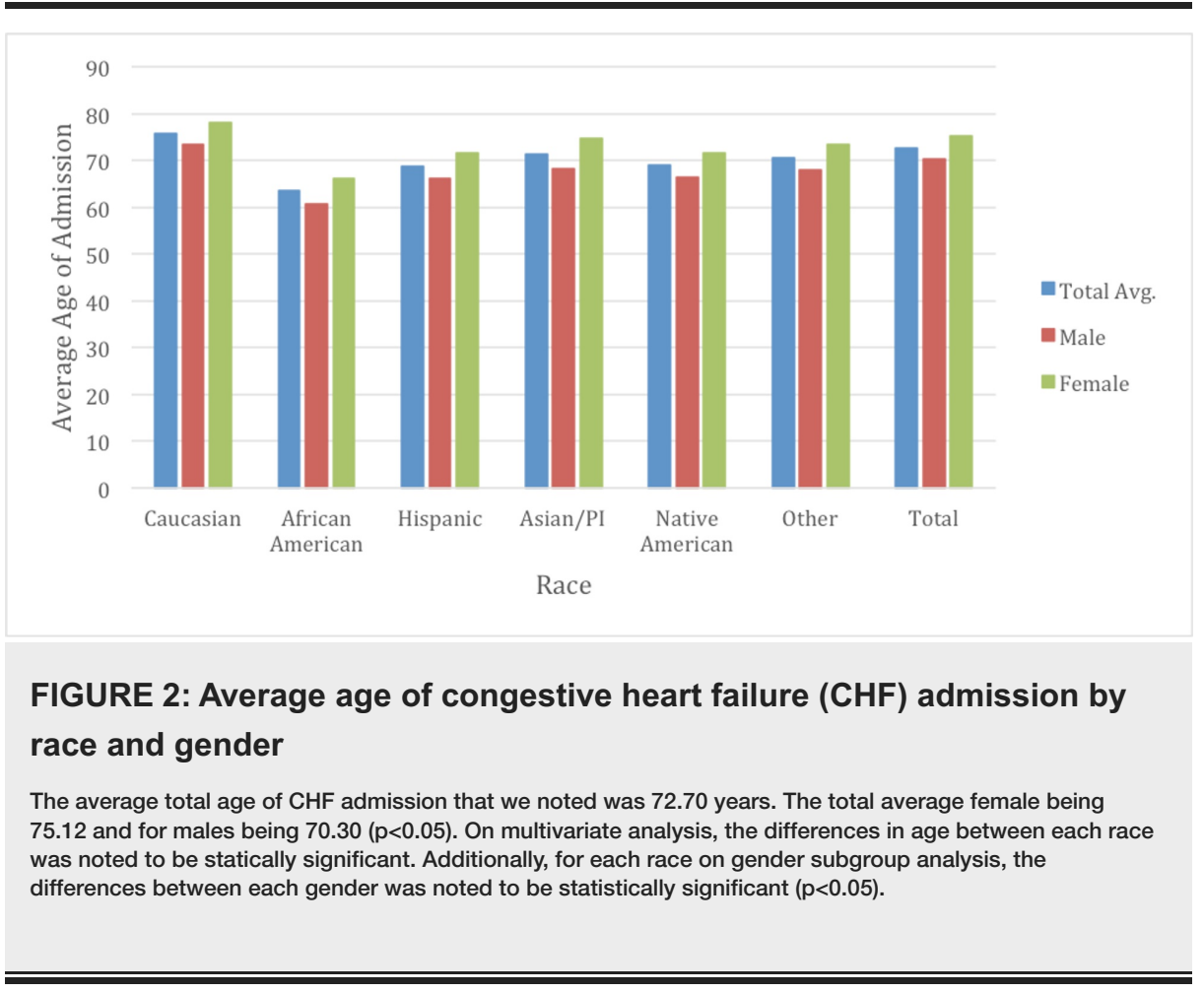

Based on race, Native Americans had the highest percentage of females presenting with $\mathrm{CHF}$ at $50.14 \%$. The lowest was the race deemed "Other" at $47.80 \%$ followed by Hispanics at $48.06 \%$. The proportion of females within the Caucasians was $49.78 \%(\mathrm{p}<0.05)$.

It was observed that Native Americans had an average LOS of 4.67 days which was significantly shorter than all other races (Figure 3). Caucasians had the second shortest LOS at 5.16 days, whereas the race specified as "Other" had the longest LOS at 5.67 days, exactly one day longer than that of Native Americans. When comparing the average total cost calculated as total charge to the patient/insurance company the results were surprising. Asians were noted to pay on average almost $\$ 25,000$ more per CHF admission than compared to Native Americans $(\$ 59,668$ vs $\$ 34,192, \mathrm{p}<0.05)$ (Figure 4). This is despite the fact that Asians had a LOS of only 0.49 days longer than Native Americans. When compared to Caucasians, Asians had a higher total charge of almost $\$ 22,000$ ( $\$ 59,668$ vs $\$ 38,034 \mathrm{p}<0.05$ ). On multivariate analysis, the differences between races studied and the total charges billed were statistically significant at all levels of analysis between races. The type of insurance billed was also analyzed looking at Payor 1 and Payor 2 for hospital admission. Caucasians were the most likely to have Medicare as Payor 1 at $81.35 \%$ while they were also the 


\section{Cureus}

most likely to have private insurance as Payor 2 at 54.08\%. African Americans were the least likely to use Medicare as Payor 1 at $58.56 \%$ but most likely to use Medicaid as Payor 1 at $18.10 \%$. Caucasians used Medicaid as Payor 1 at $3.80 \%$.

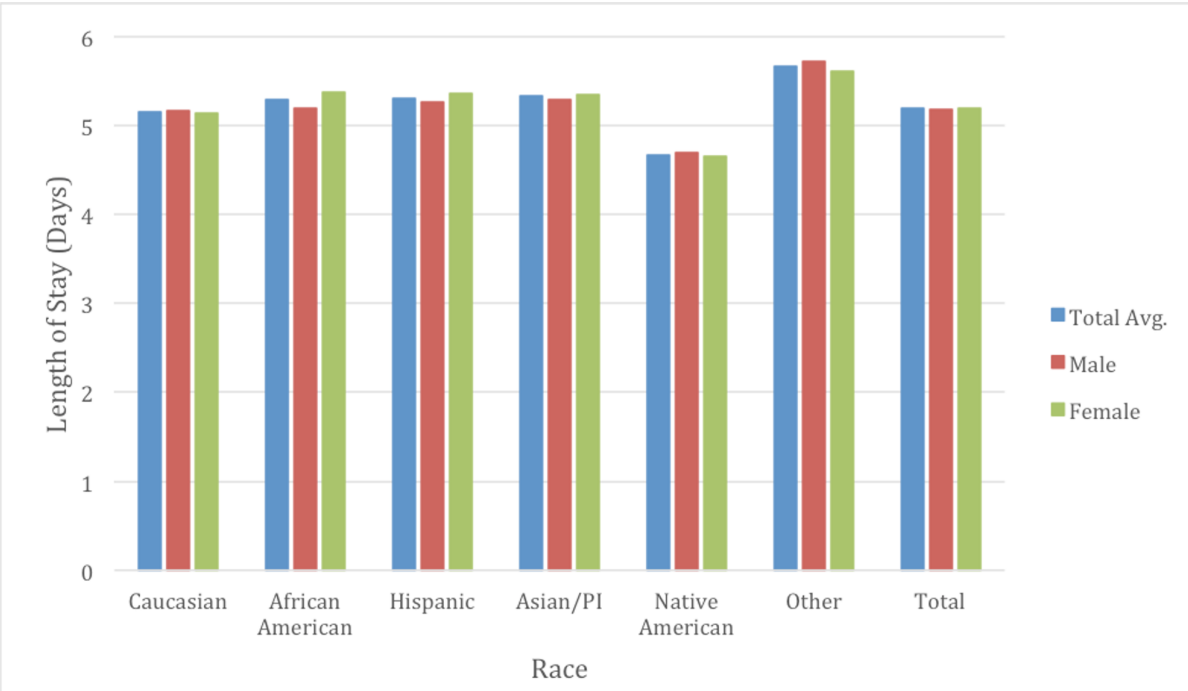

\section{FIGURE 3: Length of stay by race and gender}

Overall the average length of stay we noted was 5.19 days. Males had an average of 5.18 days while females were 5.20 days $(p<0.05)$. Native Americans were noted to have the least number of days spent in hospital for congestive heart failure (CHF) admissions. The differences between average length of stay between races was noted to be statistically significant $(p<0.05)$. Additionally, on gender subgroup analysis, the differences between each gender was noted to be statistically significant $(p<0.05)$ only for African Americans and Hispanics.

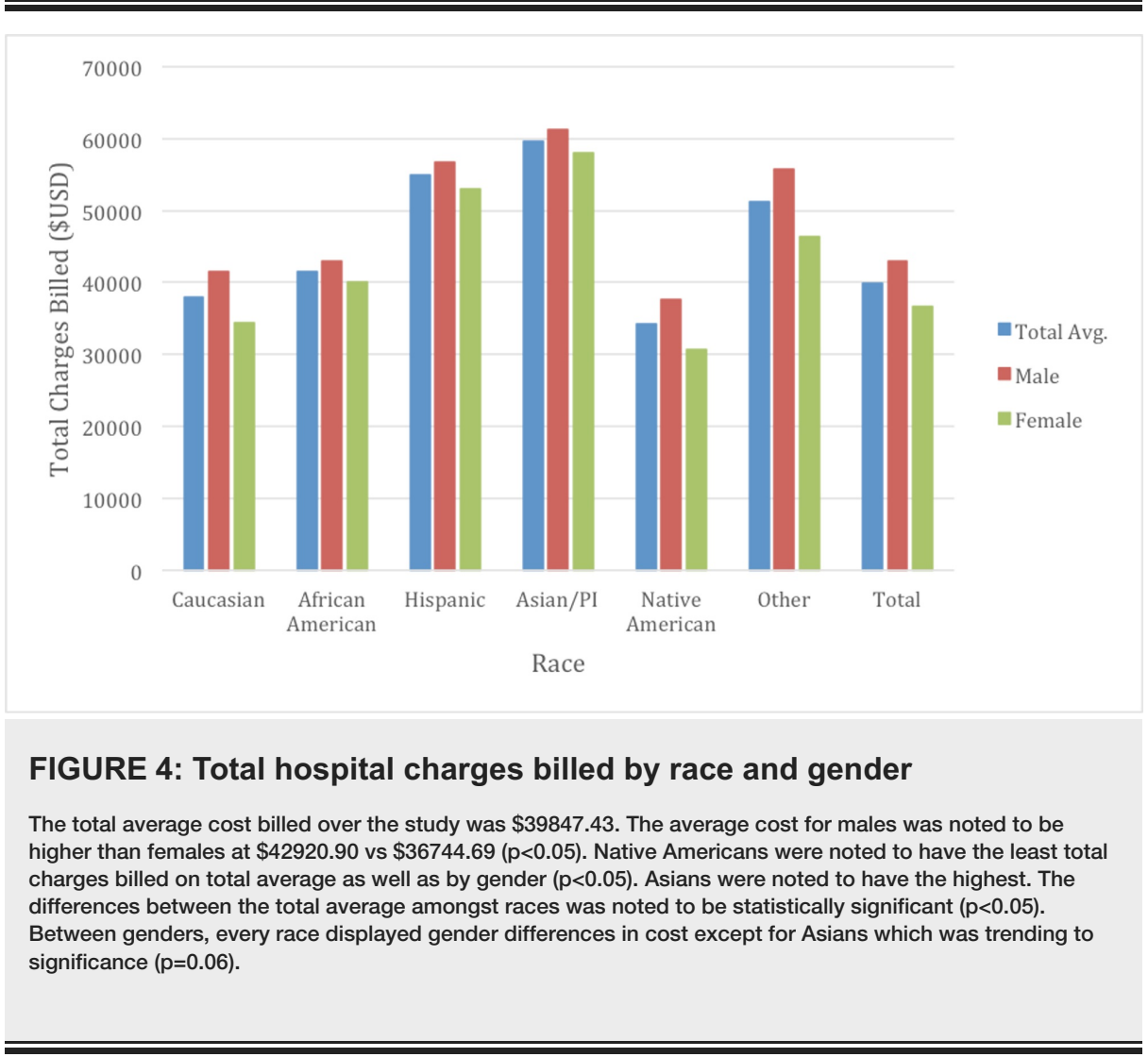

In terms of mortality, Caucasians were observed to have the highest mortality rate at $3.55 \%$ The race with the lowest mortality was African Americans at 1.75\% (Figure 5). There was no significant difference between Native Americans and Hispanics in terms of mortality rates on multivariate analysis. Interestingly, 


\section{Cureus}

Caucasians also had the highest average age at presentation at 75.76 while African Americans presented almost 12 years earlier in age at 63.47 and well below the average age amongst all races $(\mathrm{p}<0.05)$.

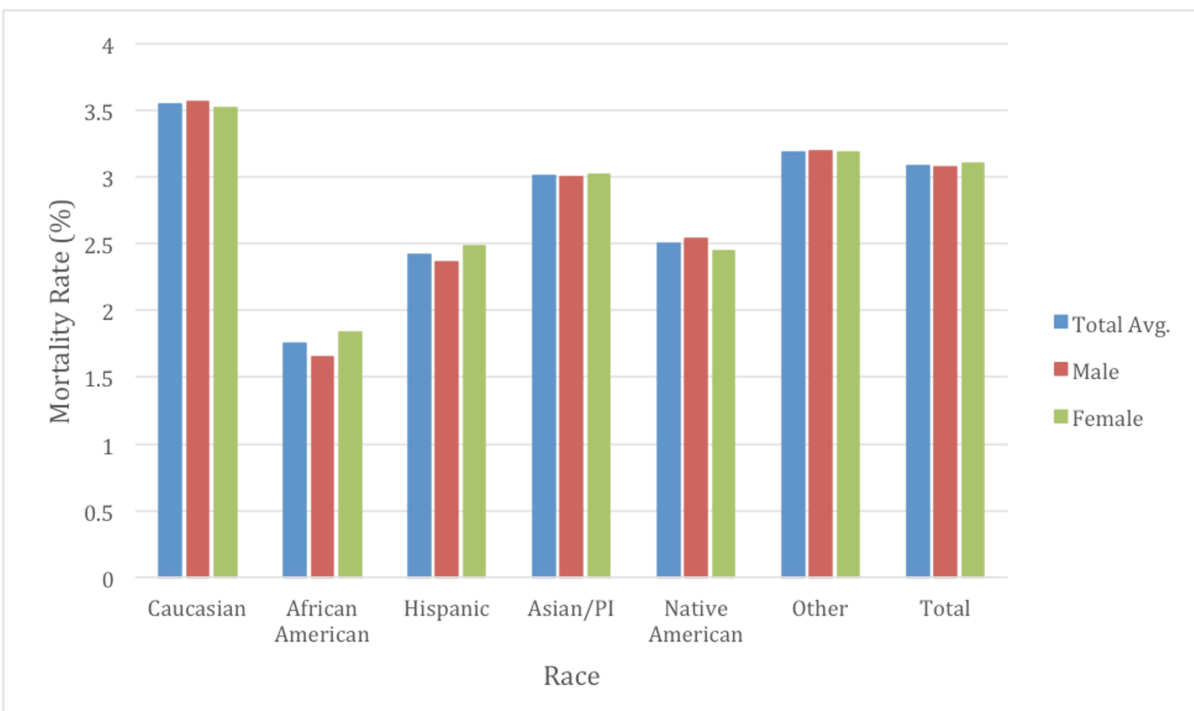

FIGURE 5: Mortality rate by race and gender

The mortality rate was seen highest with Caucasians while African Americans were seen to have the lowest mortality. The differences amongst mortality amongst all the races were statistically significant $(p<0.05)$. When comparing genders within each race, only African Americans displayed gender differences in mortality $(p<0.05)$

When comparing African Americans to Caucasians in regards to median household income quartile, it was found that Caucasians had the second highest income per ethnic group at 2.41 whereas African Americans had the lowest at 1.77. Asians were noted to have the highest income with a quartile of 2.87 . The differences between all races for income quartile was statistically significant. The average income by quartile for all CHF admissions was approximately 2.25 over the five years studied.

The number of procedures during hospitalization (NPR) conducted during CHF admissions were also examined to help determine cost differences. The average NPR completed during the study in all races was approximately 1.08 (Figure 6). Native Americans had the least number of procedures completed during their hospitalizations at 0.98 , while Asians had the second highest at $1.52(\mathrm{p}<0.05)$. Caucasians had an average of 1.02 number of procedures during their admissions. There was no statistical significance in the difference in NPR between Native Americans and Caucasians that was noted.

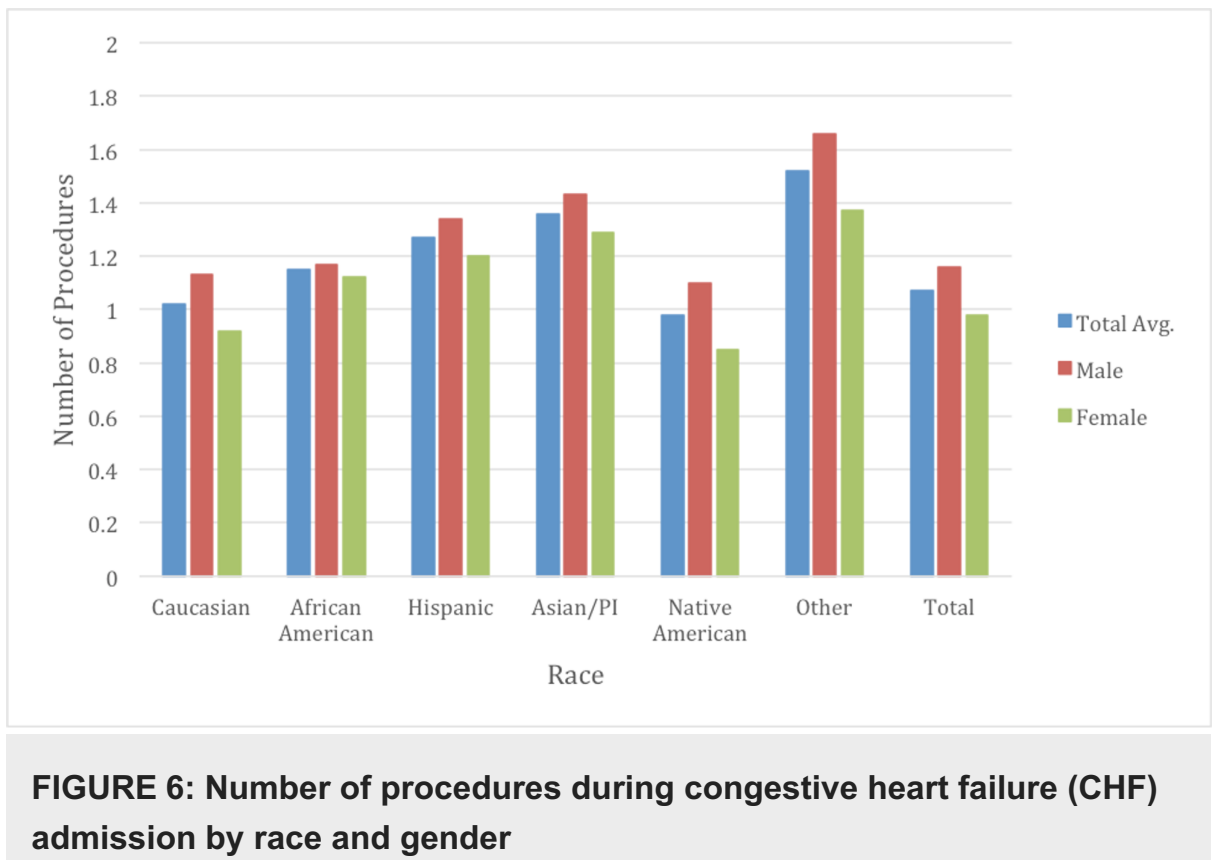




\section{Cureus}

The average number of procedures during a CHF admission was 1.07. Native Americans were noted to have the least number of procedures done during their hospitalizations. Between genders, every race displayed gender differences in numbers of procedures $(p<0.05)$.

The Elixhauser mortality index scores were also analyzed. On average, the score increased from 5.17 in 2009 to 6.06 in 2014. African Americans were noted to have the lowest Elixhauser mortality score at 4.86, whereas Asians were noted to have the highest at $6.94(\mathrm{p}<0.05)$ (Figure 7). Caucasians had an average score of 5.96. On multivariate analysis between all races, statistical significance in differences was seen between all races except between Native Americans and Hispanics.

With the Elixhauser readmit score, the average score in 2009 was 18.42 which then rose to a level of 21.42 in 2014. Caucasians were seen to have the lowest score at 19.78 while Asians had the highest at $22.21(\mathrm{p}<0.05)$ (Figure 8 ). Only between Native Americans and Caucasians was there no statistical significance found on multi-variate analysis. Comorbidities were also analyzed based off the Elixhauser comorbidities (Table 1). Overall, the comorbidity with the highest prevalence in our study was shown to hypertension at $71.82 \%$ followed by renal failure at $38.50 \%$, chronic lung disease at $36.39 \%$, and diabetes without complications at $33.74 \%$. The comorbidities seen least frequently were peptic ulcer disease at $0.03 \%$ followed by AIDS at $0.23 \%$. On analysis as a whole, only peptic ulcer disease did not have any statistical significance noted between all races $(\mathrm{p}=0.18)$.

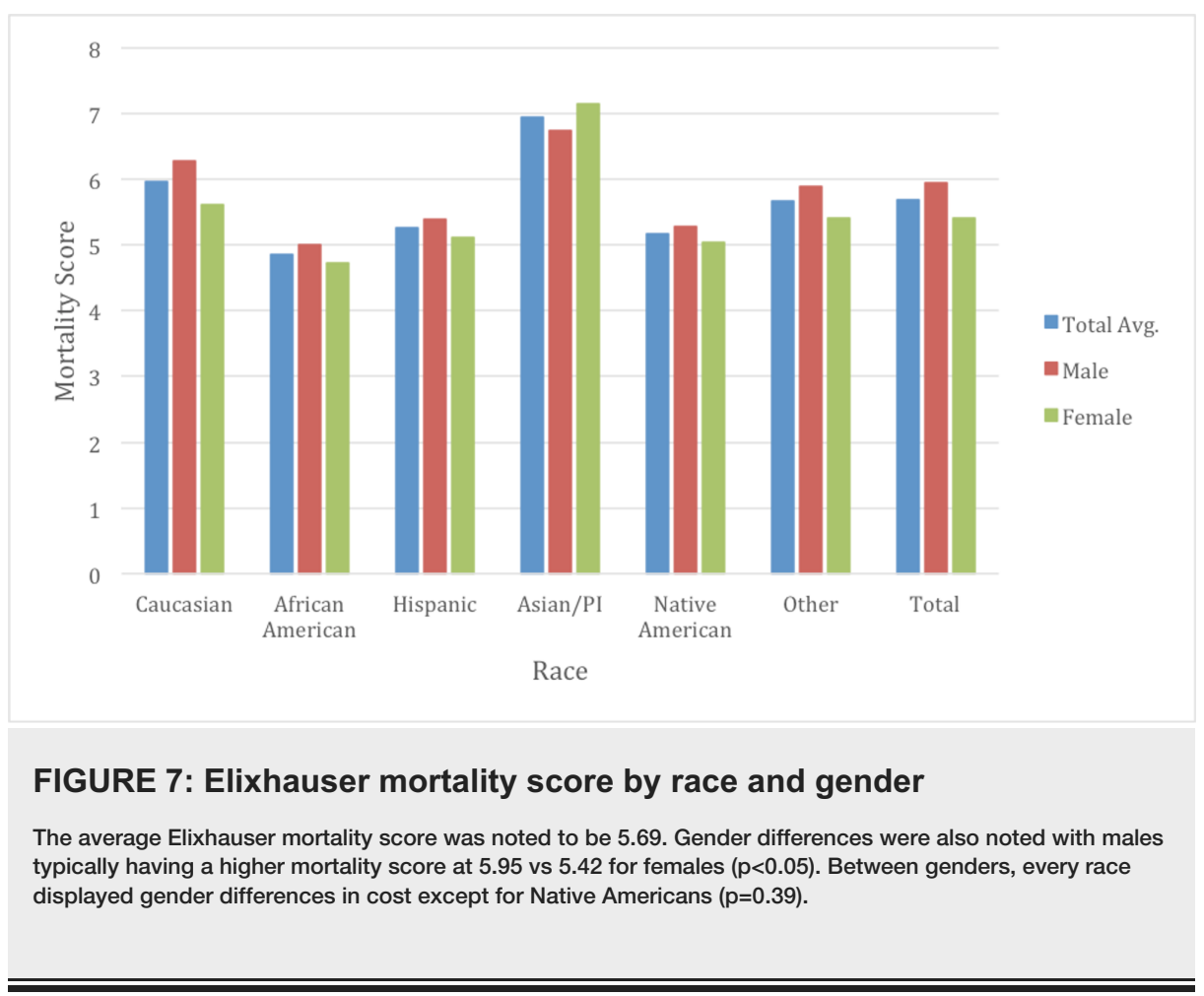




\section{Cureus}

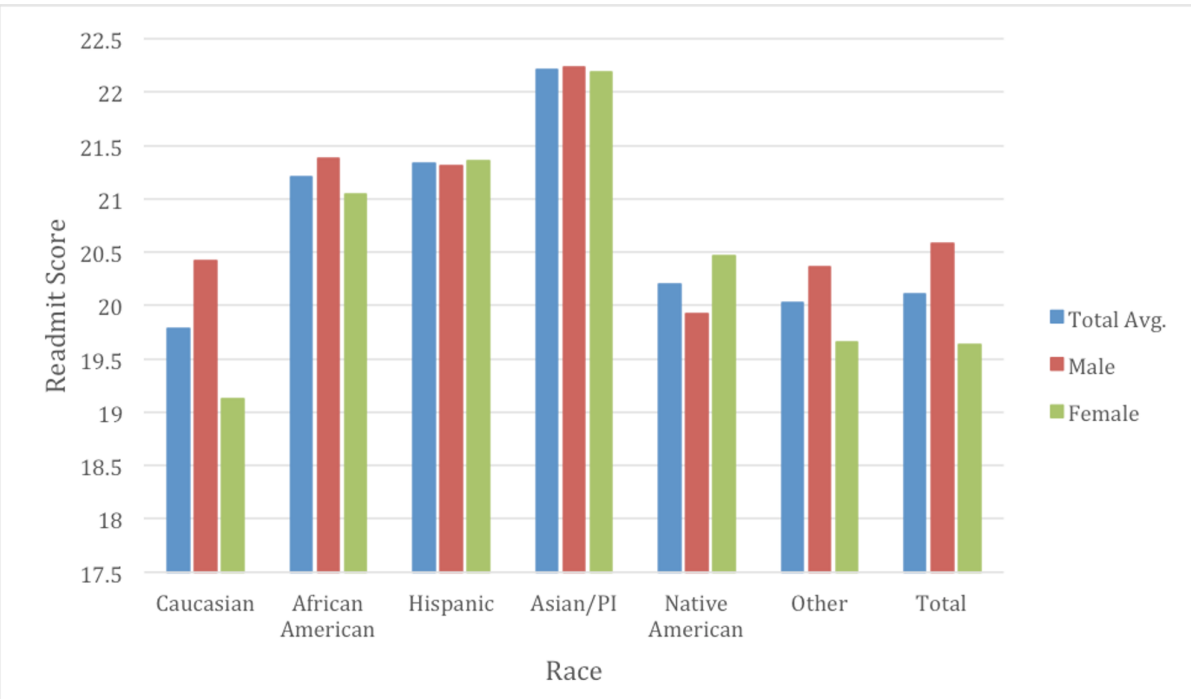

FIGURE 8: Elixhauser readmit score by race and gender

The average Elixhauser readmit score was noted to be 20.11. Gender differences were also noted with males typically having a higher readmit score at 20.58 vs 19.64 for females $(p<0.05)$. Between genders, only Caucasians, African Americans and "Other" were noted to have gender differences. 


\begin{tabular}{|c|c|c|c|c|c|c|c|}
\hline Comorbid Condition & White & Black & Hispanic & Asian & Native American & Other & $\mathrm{p}$-value \\
\hline AIDS $^{\mathrm{a}}$ & 0.05 & 0.92 & 0.29 & 0.05 & 0.04 & 0.38 & $<0.05$ \\
\hline Valvular heart disease & 0.40 & 0.32 & 0.34 & 0.51 & 0.17 & 0.40 & $<0.05$ \\
\hline Pulmonary circulation disorders & 0.30 & 0.37 & 0.30 & 0.29 & 0.04 & 0.31 & $<0.05$ \\
\hline $\mathrm{PVD}^{\mathrm{b}}$ & 12.57 & 8.42 & 11.79 & 9.25 & 9.33 & 9.77 & $<0.05$ \\
\hline Hypertension & 69.42 & 80.18 & 76.72 & 75.45 & 68.37 & 73.29 & $<0.05$ \\
\hline Paralysis & 1.54 & 2.33 & 2.03 & 3.08 & 1.35 & 1.70 & $<0.05$ \\
\hline Neurological disorders & 7.52 & 5.29 & 5.76 & 5.17 & 4.73 & 6.00 & $<0.05$ \\
\hline Chronic pulmonary disease & 38.22 & 33.72 & 30.57 & 26.69 & 32.28 & 32.57 & $<0.05$ \\
\hline Diabetes Mellitus (uncomplicated) & 31.88 & 37.00 & 41.34 & 35.70 & 38.94 & 38.10 & $<0.05$ \\
\hline Diabetes Mellitus (Complicated) & 8.66 & 10.24 & 16.16 & 15.56 & 11.89 & 10.73 & $<0.05$ \\
\hline Hypothyroidism & 18.87 & 7.67 & 13.68 & 10.58 & 14.81 & 13.74 & $<0.05$ \\
\hline Renal failure & 36.84 & 43.17 & 42.09 & 48.67 & 35.19 & 38.07 & $<0.05$ \\
\hline Liver disease & 2.17 & 3.33 & 4.35 & 3.08 & 3.18 & 3.54 & $<0.05$ \\
\hline Peptic ulcer disease & 0.03 & 0.03 & 0.04 & 0.05 & 0.04 & 0.04 & 0.18 \\
\hline Lymphoma & 1.07 & 0.73 & 0.85 & 0.73 & 0.93 & 0.94 & $<0.05$ \\
\hline Metastatic cancer & 1.10 & 0.75 & 0.74 & 0.99 & 0.67 & 0.82 & $<0.05$ \\
\hline Solid tumor without metastasis & 1.88 & 1.45 & 1.23 & 1.26 & 1.05 & 1.35 & $<0.05$ \\
\hline Rheumatold arthritis/Collagen vascular disease & 2.84 & 2.56 & 2.09 & 2.20 & 2.61 & 2.23 & $<0.05$ \\
\hline Coagulopathy & 4.94 & 4.17 & 5.21 & 7.23 & 4.23 & 5.22 & $<0.05$ \\
\hline Obesity & 13.64 & 19.88 & 15.96 & 7.81 & 15.16 & 13.96 & $<0.05$ \\
\hline Weight loss & 4.05 & 3.14 & 3.59 & 4.57 & 3.29 & 4.14 & $<0.05$ \\
\hline Electrolyte disorders & 27.67 & 25.47 & 26.76 & 30.30 & 26.65 & 26.50 & $<0.05$ \\
\hline Chronic blood loss anemia & 1.06 & 0.64 & 0.79 & 0.72 & 0.71 & 0.76 & $<0.05$ \\
\hline Deficiency anemias & 28.32 & 29.95 & 32.81 & 34.72 & 26.91 & 29.71 & $<0.05$ \\
\hline Alcohol abuse & 2.01 & 4.54 & 3.23 & 1.50 & 3.56 & 2.78 & $<0.05$ \\
\hline Drug abuse & 0.97 & 6.73 & 2.45 & 1.82 & 1.89 & 2.21 & $<0.05$ \\
\hline Psychoses & 2.64 & 3.52 & 2.84 & 1.78 & 2.02 & 2.53 & $<0.05$ \\
\hline Depression & 10.30 & 5.66 & 7.51 & 4.42 & 7.77 & 7.34 & $<0.05$ \\
\hline
\end{tabular}

TABLE 1: Analysis and comparison of Elixhauser comorbidity prevalence (\%) by race AIDS: acquired immunodeficiency syndrome, PVD: peripheral vascular disorders

Hypertension, one of the common risk factors associated with CHF was noted to have the highest prevalence in African Americans at $80.18 \%$ whereas the lowest prevalence was seen in Native Americans at $68.37 \%$ (p $<0.05$ ). Caucasians had the second lowest prevalence of hypertension at $69.42 \%$. There was no significant difference between Caucasians and Native Americans for hypertension. Renal failure was observed highest in prevalence in Asians at $48.67 \%$ while the lowest was seen in Native Americans at $35.19 \%(\mathrm{p}<0.05)$. Diabetes without complication was seen to be highest in prevalence in the Hispanic population at $41.34 \%$. The least was within the Caucasian population at $31.88 \%(\mathrm{p}<0.05)$. Obesity, considered a risk factor for ischemic cardiomyopathy, was seen highest in the African American population at $19.88 \%$ while the lowest was seen in Asians at $7.81 \%(\mathrm{p}<0.05)$. The overall average prevalence of obesity was $14.83 \%$. 


\section{Cureus}

Gender differences were also examined as a subgroup of races to determine if there were further healthcare inequalities (Table 2). The average age of males for CHF admissions was 70.3 while for females was approximately 75.1 years of age through the course of the study (Figure 2). Males typically had a higher total charge for their CHF admission with $\$ 38,702$ in 2009 vs $\$ 32,472$ with females, increasing to $\$ 47,586$ in 2014 in males and $\$ 40,885$ with females. The total average cost for males over the study was $\$ 42,920$ and $\$ 36,744$ for females $(\mathrm{p}<0.05)$. Mortality rate was observed at $3.08 \%$ in males and $3.10 \%$ in females $(p=0.63)$ (Figure 5). LOS was slightly lower on average between males and females at 5.18 and 5.20 respectively $(\mathrm{p}<0.05)$ (Figure 3). Income quartile was seen to be slightly lower in females at $2.25 \mathrm{vs} 2.26$ in males ( $\mathrm{p}<0.05)$. In terms of NPR, males had a greater number of procedures during their CHF admission at 1.16 vs 0.98 for females $(\mathrm{p}<0.05)$. Elixhauser mortality score was higher in males than females at 5.95 vs $5.42(\mathrm{p}<0.05)$. This was also true with the Elixhauser readmit score of 20.58 vs $19.64(\mathrm{p}<0.05)$. When comparing Elixhauser comorbidities, statistically significant gender differences were noted for all comorbidities except for peptic ulcer disease as well as for chronic lung disease with p-values of 0.50 and 0.23 respectively. The largest gender difference in terms of prevalence was noted with hypothyroidism with females seen at $21.66 \%$ and males at $10.13 \%(p<0.05)$. Hypertension was overall seen more prevalent in females at $73.26 \%$ vs $70.38 \%$ in males $(\mathrm{p}<0.05)$.

\begin{tabular}{|c|c|c|c|}
\hline & Males & Females & p-value \\
\hline Age & 70.30 & 75.12 & $<0.05$ \\
\hline Total Charges (\$) & 42920.90 & 36744.69 & $<0.05$ \\
\hline Length of Stay (days) & 5.18 & 5.20 & $<0.05$ \\
\hline ZIPINC ${ }^{a}$ & 2.26 & 2.25 & $<0.05$ \\
\hline$N^{N} R^{b}$ & 1.16 & 0.98 & $<0.05$ \\
\hline Readmission Score & 20.58 & 19.64 & $<0.05$ \\
\hline Mortality Score & 5.95 & 5.42 & $<0.05$ \\
\hline AIDS $^{\mathrm{C}}$ & 0.31 & 0.15 & $<0.05$ \\
\hline Valvular heart disease & 0.35 & 0.39 & $<0.05$ \\
\hline Pulmonary circulation disorders & 0.29 & 0.34 & $<0.05$ \\
\hline PVD $^{d}$ & 12.62 & 10.21 & $<0.05$ \\
\hline Hypertension & 70.38 & 73.26 & $<0.05$ \\
\hline Paralysis & 1.64 & 1.81 & $<0.05$ \\
\hline Neurological disorders & 6.04 & 7.56 & $<0.05$ \\
\hline Chronic pulmonary disease & 36.31 & 36.46 & 0.23 \\
\hline Diabetes Mellitus (uncomplicated) & 34.02 & 33.47 & $<0.05$ \\
\hline Diabetes Mellitus (Complicated) & 9.99 & 9.32 & $<0.05$ \\
\hline Hypothyroidism & 10.13 & 21.66 & $<0.05$ \\
\hline Renal failure & 41.70 & 35.34 & $<0.05$ \\
\hline Liver disease & 3.22 & 1.91 & $<0.05$ \\
\hline Peptic ulcer disease & 0.03 & 0.03 & 0.5 \\
\hline Lymphoma & 1.01 & 0.93 & $<0.05$ \\
\hline Metastatic cancer & 1.03 & 0.96 & $<0.05$ \\
\hline Solid tumor without metastasis & 2.10 & 1.32 & $<0.05$ \\
\hline Rheumatoid arthritis/Collagen vascular disease & 1.45 & 3.96 & $<0.05$ \\
\hline Coagulopathy & 5.73 & 3.94 & $<0.05$ \\
\hline Obesity & 14.01 & 15.63 & $<0.05$ \\
\hline Weight loss & 3.59 & 4.06 & $<0.05$ \\
\hline
\end{tabular}




\section{Cureus}

\begin{tabular}{|llll|}
\hline Electrolyte disorders & 25.31 & 28.94 & $<0.05$ \\
Chronic blood loss anemia & 0.80 & 1.07 & $<0.05$ \\
Deficiency anemia & 26.38 & 31.20 & $<0.05$ \\
Alcohol abuse & 4.38 & 0.77 & $<0.05$ \\
Drug abuse & 3.19 & 1.17 & $<0.05$ \\
Psychoses & 2.54 & 3.04 & $<0.05$ \\
Depression & 6.89 & 11.12 & $<0.05$ \\
\hline
\end{tabular}

TABLE 2: Observed gender differences in age, total charges, length of stay, income quartile, number of procedures, as well as Elixhauser mortality score, readmission score and

\section{comorbidities}

Comorbid conditions presented as prevalence (\%). All comorbidities were found to be statistically significant except for peptic ulcer disease and chronic lung disease.

ZIPINC: Median household income for patient's ZIP Code; NPR: Number of procedures during admission, AIDS: acquired immunodeficiency syndrome; PVD:peripheral vascular disorders.

Renal failure was more likely to be observed in males with CHF admissions at $41.70 \%$ whereas females were $35.34 \%(\mathrm{p}<0.05)$.

On subgroup analysis between races and genders, the highest average age belonged to female Caucasians at 78.02 years, whereas the lowest was African American males at 60.76 years of age. Interestingly, almost the reverse was true in terms of mortality with African American males having the lowest mortality at $1.65 \%$ with Caucasian females at the second highest at 3.52\% ( $\mathrm{p}<0.05)$. Caucasian males overall had the highest mortality at $3.57 \%$. Asian males had the highest total charges billed at $\$ 61,278$ while Native American females had the lowest at $\$ 30,688$. In terms of the Elixhauser mortality score, Asian females had the highest score at 7.15 and African American females had the lowest at $4.72(\mathrm{p}<0.05)$.

Even between each race, there were noted significant differences between the genders. Average age was noted to be statistically significant in terms of differences between genders no matter what ethnicity. Total charges were also noted to be almost similar with only Asians not showing a significant difference, but trending towards it $(\mathrm{p}=0.06)$. NPR was also noted to be statistically significant amongst genders in all races. Gender differences in mortality within race was only seen amongst African Americans with males at $1.65 \%$ and females at $1.84 \%(\mathrm{p}<0.05)$.

Amongst the Elixhauser comorbidities, hypertension, hypothyroidism, liver failure, rheumatoid arthritis/collagen vascular disease, coagulopathy, anemia deficiency, alcohol use, drug use, and depression were all noted to be statistically significant between sexes for all races ( $p<0.05$ ) (Table 3). Renal failure did not show a significant difference between males and females of Native American background at $34.61 \%$ and $35.74 \%(p=0.72)$. All other races had gender differences for renal failure with males predominating ( $p$ $<0.05)$. Out of all the comorbidities, only peptic ulcer disease as well as valvular heart disease did not show any significant differences between genders at any race. Otherwise, for every other comorbidity, there was at least one race-gender difference. 


\section{Cureus}

\begin{tabular}{|c|c|c|c|c|c|c|c|c|c|c|c|c|c|c|c|c|c|c|}
\hline \multirow[t]{2}{*}{ Comorbid Condtion } & \multicolumn{3}{|l|}{ White } & \multicolumn{3}{|l|}{ Black } & \multicolumn{3}{|c|}{ Hispanic } & \multicolumn{3}{|c|}{ Asian/PI } & \multicolumn{3}{|c|}{ Native Amer } & \multicolumn{3}{|l|}{ Other } \\
\hline & Male & Female & $\begin{array}{l}\mathrm{P}^{\mathrm{p}-} \\
\text { value }\end{array}$ & Male & Female & $\begin{array}{l}p^{\mathrm{p}-} \\
\text { value }\end{array}$ & Male & Female & $\begin{array}{l}\mathrm{p}^{\mathrm{p}-} \\
\text { value }\end{array}$ & Male & Female & $\begin{array}{l}p^{\mathrm{p}-} \\
\text { value }\end{array}$ & Male & Female & $\begin{array}{l}\mathrm{p}- \\
\text { value }\end{array}$ & Male & Female & $\begin{array}{l}\mathrm{p}- \\
\text { value }\end{array}$ \\
\hline AIDS & 0.07 & 0.02 & $<0.05$ & 1.16 & 0.69 & $<0.05$ & 0.47 & 0.11 & $<0.05$ & 0.04 & 0.06 & 0.1 & 0.07 & 0.00 & 0.99 & 0.56 & 0.19 & $<0.05$ \\
\hline Valvular heart disease & 0.39 & 0.40 & 0.2 & 0.28 & 0.36 & 0.07 & 0.31 & 0.37 & 0.49 & 0.46 & 0.55 & 0.57 & 0.14 & 0.20 & 0.75 & 0.35 & 0.45 & 0.54 \\
\hline Pulmonary circulation disorders & 0.28 & 0.31 & 0.74 & 0.34 & 0.40 & 0.37 & 0.21 & 0.40 & $<0.05$ & 0.34 & 0.23 & 0.98 & 0.08 & 0.00 & 0.32 & 0.24 & 0.38 & $<0.05$ \\
\hline PVDI & 14.17 & 10.99 & $<0.05$ & 8.31 & 8.52 & 0.56 & 12.82 & 10.70 & $<0.05$ & 9.86 & 8.62 & 0.45 & 11.04 & 7.69 & $<0.05$ & 10.90 & 8.59 & $<0.05$ \\
\hline Hypertension & 67.76 & 71.06 & $<0.05$ & 79.88 & 80.47 & $<0.05$ & 74.89 & 78.65 & $<0.05$ & 73.58 & 77.37 & $<0.05$ & 66.22 & 70.43 & $<0.05$ & 71.54 & 75.11 & $<0.05$ \\
\hline Paralysis & 1.48 & 1.60 & $<0.05$ & 2.09 & 2.57 & $<0.05$ & 2.03 & 2.03 & 0.51 & 2.84 & 3.33 & 0.07 & 1.40 & 1.30 & 0.98 & 1.50 & 1.91 & 0.9 \\
\hline Neurological disorders & 6.61 & 8.42 & $<0.05$ & 4.80 & 5.78 & $<0.05$ & 4.99 & 6.57 & $<0.05$ & 5.02 & 5.33 & $<0.05$ & 4.36 & 5.09 & $<0.05$ & 5.05 & 6.98 & $<0.05$ \\
\hline Chronic pulmonary disease & 38.82 & 37.63 & $<0.05$ & 31.73 & 35.69 & $<0.05$ & 29.69 & 31.50 & $<0.05$ & 26.72 & 26.65 & 0.51 & 33.25 & 31.35 & 0.66 & 31.99 & 33.17 & $<0.05$ \\
\hline Diabetes Mellitus (uncomplicated) & 33.29 & 30.49 & $<0.05$ & 34.10 & 39.87 & $<0.05$ & 40.08 & 42.67 & $<0.05$ & 35.00 & 36.42 & 0.99 & 38.50 & 39.36 & 0.21 & 37.13 & 39.11 & 0.1 \\
\hline Diabetes Mellitus (Complicated) & 9.37 & 7.95 & $<0.05$ & 9.41 & 11.06 & $<0.05$ & 15.73 & 16.61 & $<0.05$ & 16.16 & 14.94 & 0.23 & 11.43 & 12.33 & 0.28 & 10.71 & 10.75 & 0.29 \\
\hline Hypothyroidism & 12.17 & 25.52 & $<0.05$ & 4.40 & 10.91 & $<0.05$ & 8.83 & 18.78 & $<0.05$ & 6.87 & 14.38 & $<0.05$ & 9.82 & 19.57 & $<0.05$ & 8.65 & 19.02 & $<0.05$ \\
\hline Renal failure & 40.77 & 32.95 & $<0.05$ & 45.53 & 40.82 & $<0.05$ & 42.79 & 41.36 & $<0.05$ & 50.96 & 46.33 & $<0.05$ & 34.61 & 35.74 & 0.72 & 40.00 & 36.08 & $<0.05$ \\
\hline Liver disease & 2.68 & 1.66 & $<0.05$ & 4.33 & 2.34 & $<0.05$ & 5.52 & 3.13 & $<0.05$ & 3.56 & 2.58 & $<0.05$ & 4.42 & 1.99 & $<0.05$ & 4.35 & 2.70 & $<0.05$ \\
\hline Peptic ulcer disease & 0.03 & 0.03 & 0.71 & 0.03 & 0.03 & 0.67 & 0.04 & 0.05 & 0.99 & 0.02 & 0.07 & 0.83 & 0.00 & 0.07 & 0.16 & 0.05 & 0.03 & 0.31 \\
\hline Lymphoma & 1.14 & 0.99 & $<0.05$ & 0.69 & 0.78 & 0.09 & 0.85 & 0.85 & 0.99 & 0.74 & 0.71 & 0.71 & 0.65 & 1.20 & 0.33 & 0.91 & 0.96 & 0.99 \\
\hline Metastatic cancer & 1.17 & 1.04 & $<0.05$ & 0.69 & 0.82 & $<0.05$ & 0.69 & 0.80 & 0.07 & 1.10 & 0.87 & 0.46 & 0.76 & 0.58 & 0.84 & 0.95 & 0.68 & 0.19 \\
\hline Solid tumor without metastasis & 2.32 & 1.44 & $<0.05$ & 1.72 & 1.19 & $<0.05$ & 1.48 & 0.97 & $<0.05$ & 1.47 & 1.04 & $<0.05$ & 1.27 & 0.83 & 0.18 & 1.71 & 0.97 & $<0.05$ \\
\hline $\begin{array}{l}\text { Rheumatoid arthritis/Collagen vascular } \\
\text { disease }\end{array}$ & 1.65 & 4.02 & $<0.05$ & 1.04 & 4.07 & $<0.05$ & 0.75 & 3.50 & $<0.05$ & 1.10 & 3.34 & $<0.05$ & 1.17 & 3.99 & $<0.05$ & 1.26 & 3.23 & $<0.05$ \\
\hline Coagulopathy & 6.02 & 3.86 & $<0.05$ & 4.59 & 3.76 & $<0.05$ & 5.86 & 4.53 & $<0.05$ & 7.57 & 6.88 & $<0.05$ & 5.05 & 3.45 & $<0.05$ & 6.18 & 4.23 & $<0.05$ \\
\hline Obesity & 13.62 & 13.65 & 0.11 & 16.58 & 23.15 & $<0.05$ & 14.29 & 17.70 & $<0.05$ & 8.14 & 7.46 & $<0.05$ & 14.86 & 15.46 & 0.41 & 12.08 & 15.91 & $<0.05$ \\
\hline Weight loss & 3.76 & 4.32 & $<0.05$ & 3.04 & 3.25 & $<0.05$ & 3.31 & 3.89 & $<0.05$ & 4.19 & 4.95 & $<0.05$ & 3.11 & 3.47 & 0.41 & 3.93 & 4.35 & 0.17 \\
\hline Electrolyte disorders & 25.70 & 29.62 & $<0.05$ & 24.45 & 26.48 & $<0.05$ & 24.89 & 28.73 & $<0.05$ & 28.25 & 32.41 & $<0.05$ & 24.31 & 28.90 & $<0.05$ & 24.41 & 28.67 & $<0.05$ \\
\hline Chronic blood loss anemia & 0.97 & 1.15 & $<0.05$ & 0.42 & 0.86 & $<0.05$ & 0.64 & 0.95 & $<0.05$ & 0.48 & 0.97 & $<0.05$ & 0.48 & 0.93 & 0.14 & 0.70 & 0.82 & 0.27 \\
\hline Deficiency anemias & 26.40 & 30.22 & $<0.05$ & 26.43 & 33.43 & $<0.05$ & 29.26 & 36.54 & $<0.05$ & 30.77 & 38.78 & $<0.05$ & 22.11 & 31.48 & $<0.05$ & 26.56 & 32.96 & $<0.05$ \\
\hline Alcohol abuse & 3.40 & 0.64 & $<0.05$ & 7.72 & 1.38 & $<0.05$ & 5.80 & 0.54 & $<0.05$ & 2.67 & 0.31 & $<0.05$ & 5.77 & 1.46 & $<0.05$ & 4.73 & 0.75 & $<0.05$ \\
\hline Drug abuse & 1.38 & 0.55 & $<0.05$ & 9.84 & 3.65 & $<0.05$ & 3.87 & 0.97 & $<0.05$ & 2.68 & 0.93 & $<0.05$ & 2.51 & 1.30 & $<0.05$ & 3.48 & 0.91 & $<0.05$ \\
\hline Psychoses & 2.38 & 2.90 & $<0.05$ & 3.21 & 3.83 & $<0.05$ & 2.67 & 3.02 & $<0.05$ & 1.73 & 1.84 & $<0.05$ & 2.03 & 2.00 & 0.59 & 2.45 & 2.63 & 0.41 \\
\hline Depression & 8.00 & 12.58 & $<0.05$ & 4.06 & 7.24 & $<0.05$ & 5.75 & 9.35 & $<0.05$ & 3.51 & 5.35 & $<0.05$ & 5.71 & 9.74 & $<0.05$ & 4.93 & 9.84 & $<0.05$ \\
\hline
\end{tabular}

TABLE 3: Analysis of Elixhauser comorbidities between genders of each individual race

Comorbid conditions presented as prevalence (\%).

AIDS: acquired immunodeficiency syndrome, PVD: peripheral vascular disorders

\section{Discussion}

Chronic heart failure is one of the most common causes of inpatient stays nationally. According to the Healthcare Cost and Utilization project, it is the 4th most common reason for inpatient stay accounting for 297 stays per 100,000 [12]. It is typically a disease of the older population and can affect more than $10 \%$ of 
those older than 75 years [13]. According to the American Heart Association (AHA) we can expect the prevalence to continue to rise with the aging population. Despite the anticipated increase, our data shows the rates of hospitalizations for CHF have not increased and in fact, appeared to decrease over a six-year span. This may be attributed to improved outpatient management of heart failure, optimization of guideline-directed medical therapy, as well as the focus by CMS to decrease 30 readmissions [14]. Our data suggests, however, that this improvement in outpatient management and benefit from primary care may not be ubiquitous amongst the population. Herein, we will focus our discussion on the various health care disparities observed between ethnic groups.

Health care disparities are defined as "differences in health care quality, access, and outcomes adversely affecting members of racial and ethnic minority groups and other socially disadvantaged populations” [15]. Studies looking at these are becoming more abundant and rightfully so. The United States is projected to grow by 1.8 million per year between 2017 and 2060, with the majority of this growth coming from international migration than natural increase [16]. With an increasingly diverse population, studies on disparities amongst ethnic and racial groups become essential to identify pitfalls in our healthcare system to ensure quality and equality in the care that we deliver. These inequalities have been noted to occur in a variety of forms including patient's experience of care, preventative care, and hospitalization [15].

Differences in heart failure exacerbations amongst various ethnicities have been previously reported using the NIS. Ziaeian et al. looked at heart failure hospitalizations and differences based on sex and race using the same database from years 2002 and 2013. Their study primarily focused on age-adjusted differences in hospitalization rates between ethnic groups [17]. The purpose of our study was to further investigate areas of inequality that pertain to their hospital course and cost.

The results of the study were quite staggering with multiple differences observed amongst ethnic groups. African American males and females were noted to be a particularly vulnerable population. Our study shows on average they present over a decade younger than their Caucasian counterparts. This is consistent with previous literature showing that African-Americans are 20 times more likely to have heart failure than whites in patients less than 50 years old [18]. African American patients are also shown to have a significantly higher readmission score but have a lower mortality score than white patients despite having a longer LOS and total charge. Lee et al. noted similar findings of increase LOS and risk of readmission, however, there were no differences in cost or mortality [19]. It is difficult to speculate the reason for a longer LOS despite better outcomes and lower mortality score. Differences may arise from type of payer as the African American population had a higher percentage of Medicaid as the primary payer. Further analysis is to be done to determine differences in disposition, and whether discharge home or to skilled nursing facilities may play a role in the LOS.

Readmission scores were significantly higher in minority populations with the exception of Native American. This may be in part to inequalities of chronic disease management that arise from previously demonstrated differences in health literacy, perceived discrimination, beliefs about medication, and nonadherence related to cost [15]. This may also be explained by differences in socioeconomic status. With the exception of the Asian population, our study shows minority populations present from lower income quartiles than Caucasian patients. Philbin et al. previously demonstrated in a large population of patients in acute-care hospitals that lower income was a positive predictor of readmission risk [20].

Perhaps the most shocking difference observed in our sample of patients is the large fluctuation of total charges amongst different ethnic groups. Specifically, Asian patients are observed to have a significant increase in total cost compared to all ethnic groups, with an impressive $\$ 25,000$ difference from Native American counterparts. Indeed, when compared to Native Americans, Asian patients have a longer LOS by 0.66 days however, when we calculate the average daily cost of a CHF admission which our data approximates $\$ 9000$, this only accounts for $\$ 6000$. What about the other $\$ 19000$ ? One potential explanation is that Asian population also had an increased mortality index therefore indicating more comorbidities which may drive the increase in hospital charges. A study in France demonstrated a "super-additive" increase in cost for chronic diseases in patients with comorbid conditions due to disease interaction [21]. Chen et al. analyzed in detail healthcare expenditure among Asian American subgroups. They specifically noted that expenditure on hospitalizations was not statistically significant compared to Caucasians for Chinese, Indian, and Asian populations. There was however a large increase in expenditure in the Other Asian group which unfortunately was not further specified [22]. Interestingly, it was demonstrated by Russo et al. that Asian/Pacific Islanders had the highest rate of patient safety events while in hospital, related to both surgical and medical complications [23]. Additionally, it may also be possible that due to the higher mortality score and the assumption these patients are more ill, that different medication and advanced therapies may have been offered resulting in increased total cost. In hospital complication rates have been linked to higher costs in previous studies. In an analysis of 64 different potentially preventable complications, 48 were observed to increase hospital cost by an additional estimated 9.4\%-9.7\% [24]. We also observed that Asians have more procedures done in hospital compared to other ethnicities, which may contribute to higher cost.

The gender differences were noted on multiple levels of our analysis. We found that on average, males were paying almost \$6,200 more for CHF admissions than females were. Even with accommodating for the slightly 
longer LOS for females, males paid an average of $\$ 8,286$ per day of admission vs $\$ 7,066$ for females. This may potentially be explained by the fact that males were also seen to have more procedures done during their admission at 1.16 vs 0.98 . What is interesting is that males appear to be more ill during their hospitalization based on their Elixhauser mortality score ( 5.95 vs 5.42 p <0.05), despite presenting at on average almost five years earlier than females. Not only did females present at a later age for CHF admissions, but that the mortality was seen to be similar between the two genders, further highlighting gender disparities. There have been mixed results from previous studies regarding gender differences in mortality. A retrospective analysis of the Candesartan in Heart Failure: Assessment of Reduction of Morbidity and Mortality (CHARM) program demonstrated significantly lower all cause mortality in women, as well as decreased risk of cardiovascular death and heart failure hospitalization [25]. Similarly, Parashar et al. showed a 15\%-20\% lower risk of all-cause and cardiovascular mortality in women [26]. Though there was no mortality difference in our study, we would have anticipated higher mortality in men as they were found to have more comorbidities as demonstrated by a higher Elixhauser Mortality Score. Perhaps one explanation is female patient's presenting later in their disease course and have more severe heart failure. Our average age at presentation was greater than 70 for both males and females. A study of adults $>65$ years of age showed females used hospital services $21 \%$ less than men [27]. Furthermore, in a large study of almost 2 million hospitalizations, women were found to have less positive experience than men from issues arising communication, discharge information, and cleanliness [28]. Considering this, women may be less inclined to utilize hospital services with early signs and symptoms of worsening heart failure. Our study also shows females to have less procedures performed compared to males while inpatient. We did not further differentiate which procedures were performed but this raises the important question as to the etiology of heart failure and whether or not revascularization was required for ischemic etiologies. Sedlak et al. found that when adjusted for baseline differences, women were less likely to undergo cardiac catheterization than men when presenting with acute myocardial infarction [29]. This is an important consideration when over $60 \%$ of heart failure cases may have an underlying ischemic etiology [30].

\section{Study limitation}

With the use of a large all-payer database to conduct retrospective research, several limitations arise. Given that the data of comorbidities is deemed by ICD codes, it is possible that if diagnoses were not coded for that this may be underrepresented. Additionally, due to the NIS database being identified, there are likely instances of readmissions resulting in overrepresentation of certain factors. Also, due to the fact that medications and echocardiography results are not available, we are not truly able to determine the severity of heart failure and the contributions that gender and race may have on its development. This also can include the fact that we are unable to determine whether there were any stays within an intensive care unit or not, which would reflect increased costs charged to the patient. Furthermore, we only used primary diagnoses of CHF to eliminate the possibility of non-active CHF being incorporated into the study. The result of this is the possibility of eliminating active CHF in patients that were not coded as the primary issue during the hospitalization. Our purpose for this study was to determine the financial impact of race and gender disparities in CHF admissions.

\section{Conclusions}

In conclusion, it is clear there are several disparities observed among different ethnic groups and between genders hospitalized for CHF exacerbation. The unfortunate reality is that these disparities are deeply rooted and multifaceted and have been shown to occur at the patient, provider, and systems level. There is likely no simple fix at this time, but using this study and the emerging data on healthcare disparities especially with the increasingly diverse population of our nation - it is essential to design studies to further elucidate the source of these differences. Our goal as healthcare providers should be to continue to improve healthcare for all populations and promote cultural competency in efforts to minimize differences in patient experiences and the care we provide.

\section{Additional Information \\ Disclosures}

Human subjects: Consent was obtained by all participants in this study. Animal subjects: All authors have confirmed that this study did not involve animal subjects or tissue. Conflicts of interest: In compliance with the ICMJE uniform disclosure form, all authors declare the following: Payment/services info: All authors have declared that no financial support was received from any organization for the submitted work. Financial relationships: All authors have declared that they have no financial relationships at present or within the previous three years with any organizations that might have an interest in the submitted work. Other relationships: All authors have declared that there are no other relationships or activities that could appear to have influenced the submitted work.

\section{References}

1. HCUP-statistical brief 225: trends in hospital inpatient stays in the United States, 2005-2014 . (2017). Accessed: May 5, 2020: https://www.hcup-us.ahrq.gov/reports/statbriefs/sb225-Inpatient-US-StaysTrends.jsp.

2. Strom JB, Kramer DB, Wang Y, et al.: Short-term rehospitalization across the spectrum of age and insurance 
types in the United States. PLoS One. 2017, 12:e0180767. 10.1371/journal.pone.0180767

3. CDC: heart disease and stroke deaths hitting middle age adults in large numbers . (2018). Accessed: May 5, 2020: https://www.cdc.gov/media/releases/2018/p0906-Heart-disease-stroke-deaths.html.

4. NHE fact sheet. (2018). Accessed: May 5, 2020: https://www.cms.gov/research-statistics-data-andsystems/statistics-trends-and-reports/nationalhealthexpenddata/nhe-f....

5. Heidenreich PA, Albert NM, Allen LA, et al.: Forecasting the impact of heart failure in the United States: a policy statement from the American Heart Association. Circ Heart Fail. 2013, 6:606-619. 10.1161/HHF.0b013e318291329a

6. Egede LE: Race, ethnicity, culture, and disparities in health care. J Gen Intern Med. 2006, 21:667. 10.1111/j.1525-1497.2006.0512.x

7. LaVeist TA, Darrell G, Patrick R: Estimating the economic burden of racial health inequalities in the United States. Int J Health Serv. 2011, 41:231-238. 10.2190/HS.41.2.c

8. Smedley BD, Stith AY, Nelson AR, et al.: Racial and ethnic disparities in care: patient- and system-level factors. Unequal Treatment: Confronting Racial and Ethnic Disparities in Health Care. National Academies Press, Washington (DC); 2003.

9. Spanakis EK, Golden SH: Race/ethnic difference in diabetes and diabetic complications . Curr Diab Rep. 2013, 13:814-23. 10.1007/s11892-013-0421-9

10. Burgess DJ, Fu SS, van Ryn M: Why do providers contribute to disparities and what can be done about it? . J Gen Intern Med. 2004, 19:1154-9. 10.1111/j.1525-1497.2004.30227.x

11. CGPS: Obamacare reduces racial disparities in health coverage . (2015). Accessed: September 9, 2020: https://globalpolicysolutions.org/wp-content/uploads/2015/12/ACA-and-Racial-Disparities.pdf.

12. HCUP fast stats: Healthcare Cost and Utilization Project (HCUP) . (2019). Accessed: May 5, 2020: http://www.hcup-us.ahrq.gov/faststats/national/inpatientcommondiagnoses.jsp.

13. Metra M, Teerlink JR: Heart failure. Lancet. 2017, 390:1981-1995. 10.1016/S0140-6736(17)31071-1

14. Balakumaran K, Patil A, Marsh S, et al.: Evaluation of a guideline directed medical therapy titration program in patients with heart failure with reduced ejection fraction. Int J Cardiol Heart Vasc. 2019, 22:1-5. 10.1016/j.ijcha.2018.10.003

15. Fiscella K, Sanders MR: Racial and ethnic disparities in the quality of health care. Annu Rev Public Health. 2016, 37:375-394. 10.1146/annurev-publhealth-032315-021439

16. Demographic turning points for the United States: population projections for 2020 to 2060 . (2020). Accessed: September 9, 2020: https://www.census.gov/library/publications/2020/demo/p251144.html\#: :text=The\%20year\%202030\%20marks\%20a\%20demograph....

17. Ziaeian B, Kominski GF, Ong MK, Mays VM, Brook RH, Fonarow GC: National differences in trends for heart failure hospitalizations by sex and race/ethnicity. Circ Cardiovasc Qual Outcomes. 2017, 10:10.1161/CIRCOUTCOMES.116.003552

18. Bibbins-Domingo K, Pletcher MJ, Lin F, et al.: Racial differences in incident heart failure among young adults. N Engl J Med. 2009, 360:1179-1190. 10.1056/NEJMoa0807265

19. Lee WC, Serag H, Ohsfeldt RL, et al.: Racial disparities in type of heart failure and hospitalization . J Immigr Minor Health. 2019, 21:98-104. 10.1007/s10903-018-0727-4

20. Philbin EF, Dec GW, Jenkins PL, DiSalvo TG: Socioeconomic status as an independent risk factor for hospital readmission for heart failure. Am J Cardiol. 2001, 87:1367-1371. 10.1016/s0002-9149(01)01554-5

21. Cortaredona S, Ventelou B: The extra cost of comorbidity: multiple illnesses and the economic burden of non-communicable diseases. BMC Med. 2017, 15:216. 10.1186/s12916-017-0978-2

22. Chen J, Vargas-Bustamante A, Ortega AN: Health care expenditures among Asian American subgroups. Med Care Res Rev. 2013, 70:310-329. 10.1177/1077558712465773

23. Russo CA, Andrews RM, Barrett M: Racial and ethnic disparities in hospital patient safety events, 2005: statistical brief\# 53. Healthcare Cost and Utilization Project (HCUP) Statistical Briefs. Agency for Healthcare Research and Quality, Rockville (MD); 2006.

24. Fuller RL, McCullough EC, Bao MZ, Averill RF: Estimating the costs of potentially preventable hospital acquired complications. Health Care Financ Rev. 2009, 30:17-32.

25. O'Meara E, Clayton T, McEntegart MB, et al.: Sex differences in clinical characteristics and prognosis in a broad spectrum of patients with heart failure. Circulation. 2007, 115:3111-3120. 10.1161/CIRCULATIONAHA.106.673442

26. Parashar S, Katz R, Smith NL, Arnold AM, Vaccarino V, Wenger NK, Gottdiener JS: Race, gender, and mortality in adults $\geqslant 65$ years of age with incident heart failure (from the Cardiovascular Health Study). Am J Cardiol. 2009, 103:1120-1127. 10.1016/j.amjcard.2008.12.043

27. Cameron KA, Song J, Manheim LM, Dunlop DD: Gender disparities in health and healthcare use among older adults. J Womens Health. 2010, 19:1643-1650. 10.1089/jwh.2009.1701

28. Elliott MN, Lehrman WG, Beckett MK, Goldstein E, Hambarsoomian K, Giordano LA: Gender differences in patients' perceptions of inpatient care. Health Serv Res. 2012, 47:1482-1501. 10.1111/j.14756773.2012.01389.x

29. Sedlak TL, Pu A, Aymong E, Gao M, Khan N, Quan H, Humphries KH: Sex differences in coronary catheterization and revascularization following acute myocardial infarction: time trends from 1994 to 2003 in British Columbia. Can J Cardiol. 2010, 26:360-364. 10.1016/s0828-282x(10)70410-4

30. He J, Ogden LG, Bazzano LA, Vupputuri S, Loria C, Whelton PK: Risk factors for congestive heart failure in US men and women: NHANES I epidemiologic follow-up study. Arch Intern Med. 2001, 161.7:996-1002. 10.1001/archinte.161.7.996 